\title{
PREPARAÇÃO E CARACTERIZAÇÃO DE CATALISADOR A BASE DE COBALTO SUPORTADO EM ALUMINA PELO MÉTODO DE IMPREGNAÇÃO AO PONTO ÚMIDO
}

\author{
L. H. BERNARDES ${ }^{1}$, G. R. CÁCERES ${ }^{1}$ e A. R. C. MUNIZ ${ }^{1}$ \\ ${ }^{1}$ Universidade Federal do Pampa, Departamento de Engenharia Química \\ E-mail para contato: leticiabernardes25@outlook.com
}

\begin{abstract}
RESUMO - Desde sua descoberta, os catalisadores se tornaram fundamentais para a indústria química. Muitos processos só podem acontecer devido à utilização de catalisadores, como é o caso da síntese de Fischer-Tropsch, que utiliza como fase ativa metais de transição como Fe, $\mathrm{Ni}$, Co e Ru. Os catalisadores a base de cobalto possuem como vantagens maior resistência à desativação pela água, alta atividade, seletividade a hidrocarbonetos de cadeia longa e menor atividade para reação de deslocamento. Além disso, os catalisadores contendo cobalto são quase que exclusivamente do tipo suportados devido ao alto custo deste metal. Este trabalho teve como objetivo analisar a incorporação do óxido de cobalto em alumina comercial através da técnica de impregnação ao ponto úmido. As análises empregadas neste trabalho foram a fisissorção de $\mathrm{N}_{2}$ pelo método de BET e difratometria de raio-X. Através da fisissorção de $\mathrm{N}_{2}$ pôde-se obter a isoterma do catalisador, que correspondeu ao tipo IV e características do catalisador como uma área superficial de $151,42 \mathrm{~m} / \mathrm{g}$, um volume de poros igual a 48,63 cc/g e diâmetro de poro de 4,76 nm. Já no difratograma de raio-X, pôde-se observar picos a $19^{\circ}, 31,35^{\circ}, 36,95^{\circ}, 44,95^{\circ}, 59,5^{\circ}, 65,5^{\circ}, 77,65^{\circ}$ e $94,4^{\circ}$, que são correspondentes ao $\mathrm{Co}_{3} \mathrm{O}_{4}$.
\end{abstract}

\section{INTRODUÇÃO}

Catálise é um fenômeno em que reações químicas são aceleradas através de substâncias ativas, chamadas de catalisadores (Deutschamann et al., 2009). Estes catalisadores podem ser sólidos, líquidos ou até mesmo gases. Normalmente, eles apresentam uma composição complexa e características muito restritas para cada transformação química, sendo constituídos por uma ou mais fases ativas e depositado sobre um suporte, a fim de apresentar uma área específica máxima.

Catalisadores são, geralmente, classificados de acordo com suas propriedades e relacionados com um dado tipo de reação, que podem ser de hidrogenação, oxidação, esterificação, isomerização, etc (SILVA; RODRIGUES; NONO, 2008).

Catalisadores suportados desempenham papel fundamental em processos industriais, como, por exemplo, na Síntese de Fischer-Tropsch. Esta síntese visa a produção de combustíveis sintéticos, com as mesmas propriedades dos derivados convencionais do 
petróleo, a partir do gás de síntese, que é composto, prioritariamente, por uma mistura de $\mathrm{H}_{2}$ e CO, proveniente da gaseificação de carvão mineral ou biomassa (SOUZA, 2007).

De acordo com Dry (2002), os catalisadores mais empregados na reação de FischerTropsch possuem como fase ativa metais de transição, tais como ferro, níquel, cobalto e rutênio. A escolha do metal utilizado no processo depende do tipo de tecnologia empregada na reação e do produto que se pretende obter.

O catalisador contendo cobalto como metal ativo possui alta atividade para hidrogenação, tendendo a formar, principalmente, alcanos lineares (O'BRIEN et al., 1997). Assim como descrito por Souza (2007), a síntese de catalisadores de cobalto com alto grau de dispersão requer a formação inicial de cristalitos pequenos do óxido de cobalto. Estes catalisadores altamente dispersos possuem uma forte interação entre o suporte e os precursores do metal.

$\mathrm{Na}$ escolha do suporte, o tamanho dos poros tem grande efeito na transferência de massa de reagentes e produtos. Para a síntese de Fischer-Tropsch, os suportes mais utilizados são os materiais mesoporosos, como, por exemplo, zeólita, sílica e alumina. Segundo Deutschamann et al. (2009), o suporte utilizado e o método de incorporação do metal influencia diretamente no desempenho catalítico, na dispersão dos metais, na estabilidade e na difusão dos reagentes de reação.

Este trabalho teve como objetivo preparar e caracterizar um catalisador de cobalto suportado em alumina através do método de impregnação ao ponto úmido visando sua utilização na síntese de Fischer-Tropsch.

\section{MATERIAIS E MÉTODOS}

Para realização da impregnação ao ponto úmido, a quantidade da solução de $\mathrm{Co}\left(\mathrm{NO}_{3}\right)_{2} 6 \mathrm{H}_{2} \mathrm{O}$ utilizada foi de acordo com a quantidade do volume de poros da alumina obtida através da análise de fisissorção de $\mathrm{N}_{2}$, pelo método de adsorção BET.

A alumina comercial (PURALOX SBa-200, Sasol) foi seca em estufa, durante 24h, a $105^{\circ} \mathrm{C}$, antes da adição do metal. Subsequentemente, o suporte foi impregnado com o precursor metálico com a quantidade de $10 \%(\mathrm{~m} / \mathrm{m})$ de cobalto. A solução foi gotejada lentamente sobre o suporte, com agitação constante, de modo que o metal permanecesse disperso, até o seu volume final. Em seguida, o suporte impregnado foi seco em estufa a $105^{\circ} \mathrm{C}$, durante $24 \mathrm{~h}$.

Para a caracterização do óxido de cobalto em alumina, a análise de fisissorção de $\mathrm{N}_{2}$ pelo método BET (Quantachrome Instruments, modelo Nova 4200e) foi realizada para determinação do volume e diâmetro de poros e área superficial e para obter a isoterma do catalisador. Já a difratometria de raio X, utilizando um difratômetro Rigaki Dmax, com radiação $\mathrm{Cu} / \mathrm{K} \alpha$ para o intervalo de $2 \theta$ de 15 a $105^{\circ}$, foi feita para identificar as fases cristalinas do catalisador impregnado.

\section{RESULTADOS E DISCUSSÃO}


Os resultados da análise de fisissorção de $\mathrm{N}_{2}$, suporte e catalisador impregnado, estão apresentados na Tabela 1.

Tabela 1 - Resultado da análise de fisissorção de $\mathrm{N}_{2}$, pelo método BET.

\begin{tabular}{|c|c|c|c|}
\hline Amostra & $\begin{array}{c}\text { Volume dos poros } \\
(\mathrm{cc} / \mathrm{g})\end{array}$ & $\begin{array}{c}\text { Área superficial específica } \\
\left(\mathrm{m}^{2} / \mathrm{g}\right)\end{array}$ & Diâmetro do poro (nm) \\
\hline \hline Alumina pura & 53,87 & 167,96 & 5,71 \\
\hline Alumina impregnada com Co & 48,63 & 151,42 & 4,76 \\
\hline
\end{tabular}

Observa-se, através dos resultados apresentados na Tabela 1, que houve uma redução de, aproximadamente, $10 \%$ nos resultados da área superficial e do volume e $16 \%$ de diminuição no diâmetro do poro, após impregnação do cobalto. De acordo com Costa, Albuquerque e Souza (2016), este resultado é esperado devido ao bloqueio dos poros do suporte pelo óxido de cobalto, formado pela decomposição dos sais impregnados. Além disso, o valor encontrado para o diâmetro dos poros confirma que o suporte utilizado é mesoporoso, pois seu diâmetro de $5,71 \mathrm{~nm}$ se enquadra na faixa (2 a $50 \mathrm{~nm}$ ) que o classifica como este tipo de material (CANEPPELE, 2015).

A Figura 1 apresenta o difratograma obtido para o suporte impregnado com metal.

Figura 1 - Difratometria de Raio-X para a alumina impregnada.

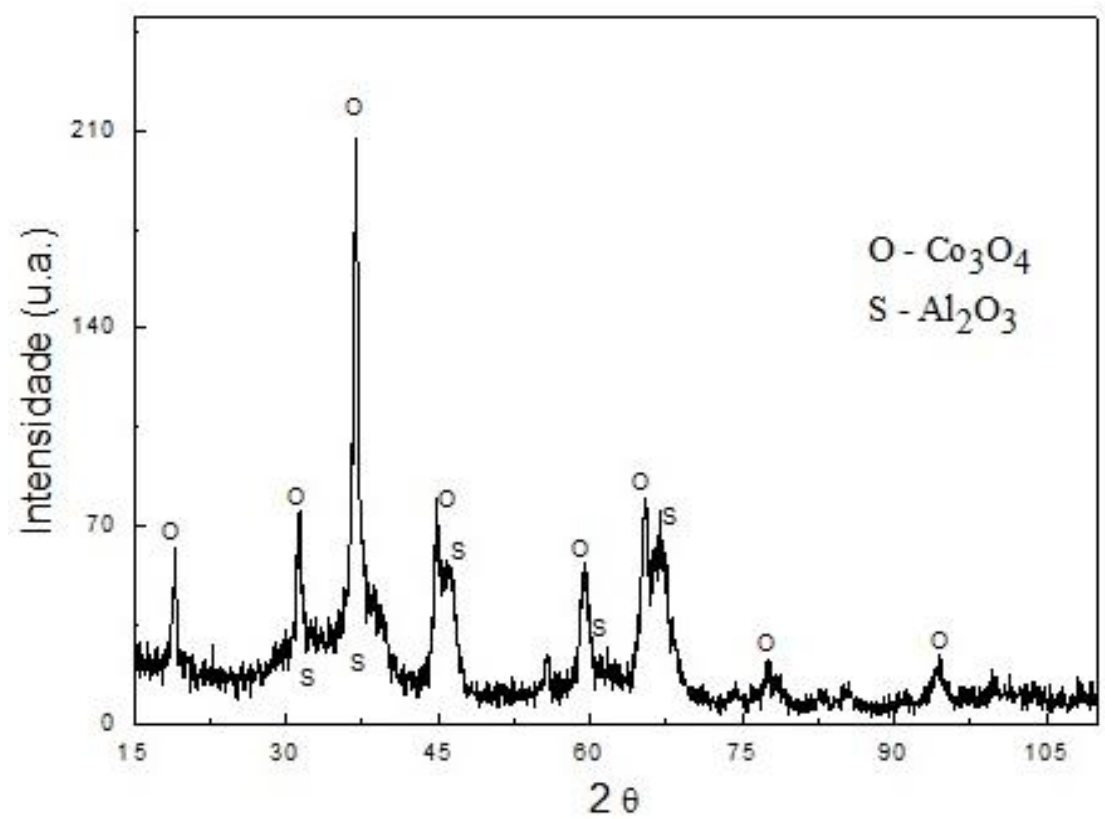

Por meio do difratograma da Figura 1, pode-se observar a presença de picos que indicam a formação de espécies $\mathrm{Co}_{3} \mathrm{O}_{4}$ no catalisador. Os picos a $19^{\circ}, 31,35^{\circ}, 36,95^{\circ}, 44,95^{\circ}$, $59,5^{\circ}, 65,5^{\circ}, 77,65^{\circ}$ e $94,4^{\circ}$ indicam que as espécies de cobalto foram, principalmente, na forma de espinela de $\mathrm{Co}_{3} \mathrm{O}_{4}$.

A Figura 2 mostra a isoterma de adsorção e dessorção para o catalisador preparado. 
Figura 2 - Isoterma do catalisador de cobalto através da fisissorção de $\mathrm{N}_{2}$ pelo método de BET.

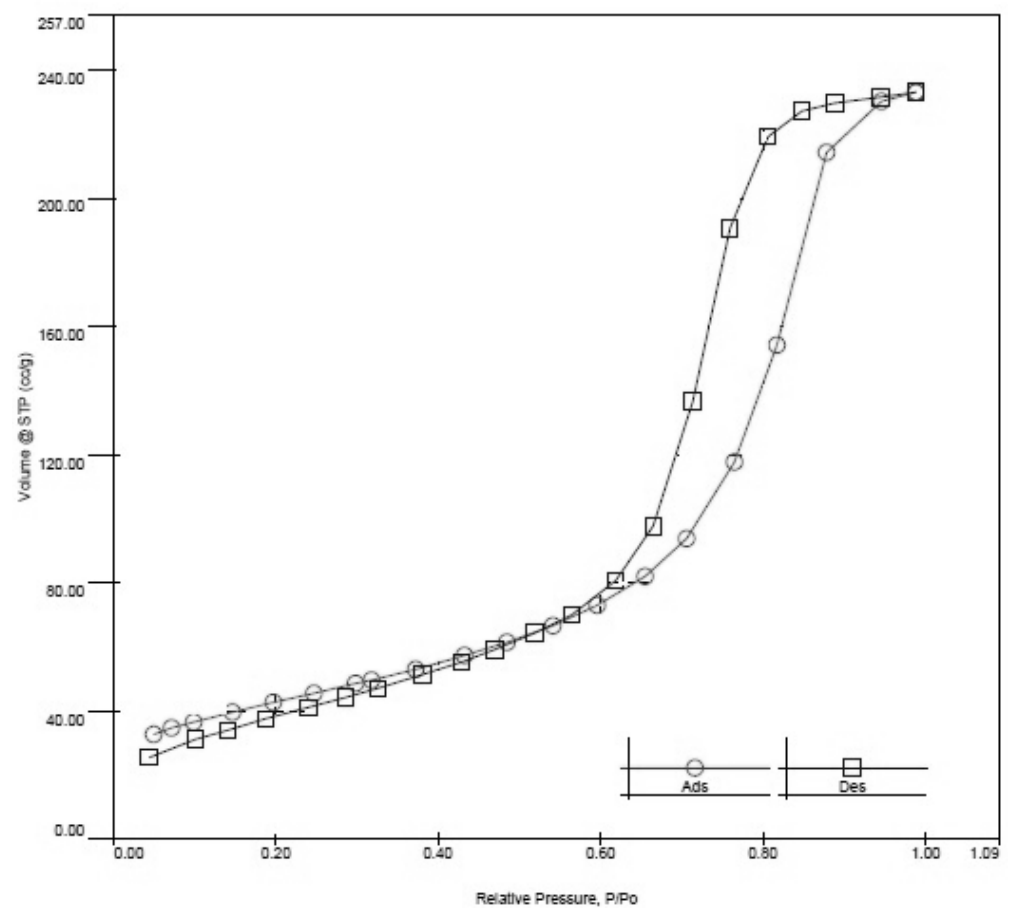

Segundo a classificação de Brunauer, a isoterma apresentada na Figura 2 é do tipo IV. De acordo com Souza (2009), existem 3 regiões em uma isoterma. A primeira região é observada em pressões relativas $\left(\mathrm{P} / \mathrm{P}_{0}\right)$ abaixo de 0,2 , que corresponde a adsorção $\mathrm{N}_{2}$ na monocamada. Já na segunda região, que é dada por $\mathrm{P} / \mathrm{P}_{0}$ entre 0,4 e 0,8 , ocorre a condensação capilar característica de materiais mesoporosos. Por fim, a terceira região, em $\mathrm{P} / \mathrm{P}_{0}$ maior que 0,9, ocorre a adsorção das multicamadas da superfície externa.

\section{CONCLUSÃO}

Diante dos resultados obtidos, confirmou-se, através do método BET, uma diminuição da área específica, do volume e diâmetro de poros da alumina após impregnação do cobalto. Já a isoterma teve seu comportamento semelhante ao modelo de isoterma de material mesoporoso do tipo IV, indicando 3 regiões distintas bem definidas. Além disso, através do difratograma, observou-se picos correspondentes a estrutura cristalina referente ao $\mathrm{Co}_{3} \mathrm{O}_{4}$, devido à decomposição do sal empregado.

\section{REFERÊNCIAS}

BRUNAUER, S. The Adsorption of Gases and Vapors.Oxford: University Press, 1945.

CAPENNELE, C. D. G. Síntese de materiais mesoporosos com arranjo hexagonal ordenado de poros, modificados com grupos orgânicos de interesse. Dissertação (Mestrado) Programa de pós-graduação em química (PPGQ) - Universidade Federal do Rio Grande do Sul, 2015. 
COSTA, F. O.; ALBUQUERQUE, J.S.; SOUZA, B.V. Comparação de diferentes técnicas de incorporação do óxido de cobalto na peneira molecular SBA-15. In: Congresso Brasileiro de Engenharia em Ciência dos Materiais, 22, 2016, Natal-RN.

DEUTSCHMANN, O.; KNÖZINGER, H.; HOCHLOEFL, K.; TUREK,T. Heterogeous Catalysis and Solid Catalysts. Ullmann's Encyclopedia of Industrial Chemistry, 2009.

DRY, M, E. The Fischer-Tropsch process: 1950-2000. Catalysis Today, v. 71, p. 227-241, 2002.

O’BRIEN, R.J.; XU, L.; SPICER, R. L.; BAO, S.; MILBURN,D. R.; DAVIS, B. H. Activity and selectivity of precipitated iron Fischer-Tropsch catalysis. Catalysis Today, v. 36, p. 325-334, 1997.

SILVA, J. B.; RODRIGUES, J. A.; NONO, M. C. A., Caracterização de materiais catalíticos. Tese (Doutorado) - Instituto Nacional de Pesquisas Espaciais (INPE), 2008.

SOUZA, B. V. Desenvolvimento de catalisadores (Co/MCM-41) destinados a reação de Fischer-Tropsch. Tese (Doutorado em Engenharia de Processos) - Universidade Federal do Paraíba. Campina Grande - PB, 2009.

SOUZA, C. D. D. Catalisadores bimetálicos para a síntese de Fischer-Tropsch. Tese (Doutorado em Engenharia Química) - Universidade Federal do Rio de Janeiro - RJ, 2007. 